Der Hanns-Lilje-Preis 2010 wurde Herrn Christopher Spehr, Münster, für seine Arbeit „Luther und das Konzil. Zur Entwicklung eines zentralen Themas in der Reformationszeit" verliehen.

\title{
Das Konzil als Reformationsort? Martin Luthers Position zur Institution der allgemeinen Kirchenversammlung
}

\section{Christopher Spehr}

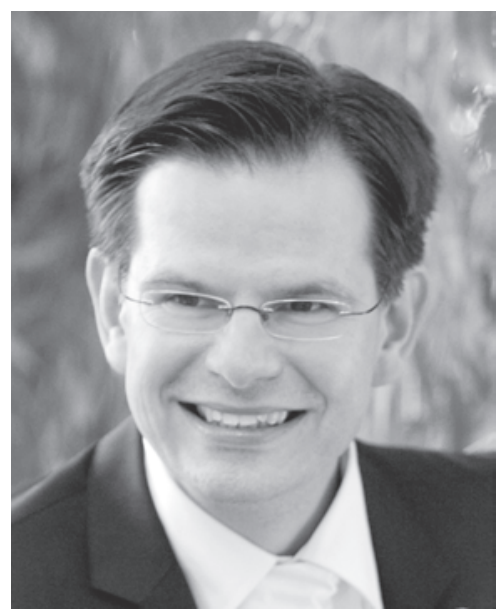

Christopher Spehr, Privatdozent an der Evangelisch-Theologischen Fakultät der Westfälischen Wilhelms-Universität Münster und Lehrstuhlvertreter für Kirchengeschichte an der FriedrichSchiller-Universität Jena, Träger des Hanns-Lilje-Preises 2010
"Jetzt aber ist ganz Deutschland in hellem Aufruhr. Neun Zehntel erheben das Geschrei: ,Luther ${ }^{r}$ und für das übrige Zehntel, falls ihm Luther gleichgültig ist, lautet die Losung: ,Tod dem römischen Hofe!' Jedermann fordert und kreischt ,Konzil', ,Konzil', will es in Deutschland haben, und selbst die, welche am meisten für uns, ja für sich selbst sorgen sollten, wollen es teils aus Furchtsamkeit, teils aus Trotz, teils aus anderen Absichten."1

Es war kein geringerer als der päpstliche Nuntius Aleander, der diese Worte 1521 vom Reichstag zu Worms nach Rom meldete. Überdeutlich skizzierte er die doppelte Gefahr, die sich für die römische Kurie im Heiligen Römischen Reich deutscher Nation zusammenbraute und in Worms zu vereinigen schien: Die Begeisterung für Luther und dessen neue Lehre und die Forderung nach einem Konzil als Ort der Kirchenreform. In der Tat war es Martin Luther selbst gewesen, der im Spätsommer

Siehe Paul Kalkoff (Hg.), Die Depeschen des Nuntius Aleander vom Wormser Reichstag 1521 (SVRG 17), Halle a.d. Saale 1886, 43 Nr. 6 (Aleander an den Vizekanzler Medici, Worms [8.2.1521]). - Die Abkürzungen orientieren sich an: Abkürzungen Theologie und Religionswissenschaften nach RGG ${ }^{4}$, Tübingen 2007. 
1520 das Konzil als Reformationsort öffentlichkeitswirksam gefordert hatte. In seiner Adelsschrift ${ }^{2}$ hatte er die weltliche Obrigkeit aufgefordert, die Reform der Christenheit persönlich in die Hand zu nehmen und ein Konzil einzuberufen. Seitdem bestimmte der Ruf nach einem Konzil das kirchenpolitische Tagesgeschäft.

Aber was verstand derjenige, der die Reformation angestoßen hatte, genauer unter einem Konzil? Und inwiefern konnte es für Luther als Reformationsort dienen? Auf diese von der Reformationsgeschichtsforschung bisher vernachlässigten Fragen möchte ich meine skizzenhaften Ausführungen anhand von fünf Punkten konzentrieren. Für die umfangreicheren Zusammenhänge verweise ich auf meine Studie „Luther und das Konzil“.”3

\section{$I$.}

Seit der Zeit der Alten Kirche bilden die Konzilien die zentralen Leitungsund Entscheidungsgremien der Christenheit. Im Verlauf des Mittelalters etablierte sich in der lateinischen Westkirche ein differenziertes System von Diözesan- und Provinzialsynoden sowie von Gesamtkonzilien, das im 14. und im 15. Jahrhundert theologisch und kirchenrechtlich reflektiert und in wachsender Konkurrenz zur päpstlichen Gewalt pointiert wurde. Als Instrument der Kirchenreform und zur Abstellung des päpstlichen Schismas erhielten die Reformkonzilien des 15. Jahrhunderts - allen voran das Konzil von Konstanz (1414-1418) - für die katholische Kirche wegweisende Bedeutung. ${ }^{4}$ Weil das Papsttum in der Folgezeit erneut erstarkte, kam es zu heftigen Auseinandersetzungen über die leitende Kirchentheorie. Die Vertreter des „Konziliarismus“ stritten für eine kollegiale Leitung der Kirche mittels eines Konzils als oberster Autorität, während die Vertreter des „Papalismus“ erfolgreich für die souveräne Primatstellung des römischen Papstes kämpften.

Der junge Theologieprofessor Martin Luther gehörte vor 1518 weder der konziliaristischen Partei an, noch hegte er besondere Neigungen zu historischen Konzilien oder zur Konzilsidee. Über die Institution des Konzils äußerte er sich in seinen erhaltenen Schriften kaum. Erst durch den Ablassstreit und die Eröffnung des kurialen Ketzerverfahrens sollte sich dies

$2 \quad$ Siehe Martin Luther, An den christlichen Adel deutscher Nation von des christlichen Standes Besserung (1520), in: WA 6; (381) 404-469.

3 Vgl. Christopher Spehr, Luther und das Konzil. Zur Entwicklung eines zentralen Themas in der Reformationszeit (BHTh 153), Tübingen 2010.

4 Vgl. z. B. Jürgen Miethke und Lorenz Weinrich (Hg.), Quellen zur Kirchenreform im Zeitalter der großen Konzilien des 15. Jahrhunderts. 2 Teile (AQDGMA 38), Darmstadt 1995-2002. 
ändern. Im Streit um die Autorität des Papstes begann er, der Institution des Konzils zunehmend Aufmerksamkeit zu schenken. Das allgemeine Konzil galt ihm jetzt als Approbationsinstanz kirchlicher Lehren, alleinige Entscheidungsinstanz in Glaubensdingen und Ort kirchlicher Reformen. ${ }^{5}$ Außerdem definierte er das Konzil als Repräsentation der Gesamtkirche. Kriterium für seine Rechtmäßigkeit war die Versammlung im Heiligen Geist. ${ }^{6}$ Damit schloss sich Luther dem konziliaristisch geprägten Konzilsverständnis an. Aber anders als von seinem Gegner Silvester Prierias vermutet, entwickelte Luther hieraus kein konziliaristisches System. Er bediente sich konziliarer Argumente nur, um das Papstamt zu kritisieren und um seine zunehmend christologisch fundierte Ekklesiologie zu ventilieren. Gleichwohl diente die Institution des Konzils seiner persönlichen Verteidigung.

Im Herbst 1518 hatte sich der Ketzerprozess gegen Luther zugespitzt. Weil Luther seine Lehre nicht widerrufen hatte, ging es für ihn jetzt um Leben und Tod. In dieser für Luther höchst dramatischen Situation trat er Ende November 1518 in der Wittenberger Fronleichnamskapelle vor Notar und Zeugen und ließ eine beurkundete Konzilsappellation anfertigen. Mit diesem juristischen Schritt hoffte er, den Ketzerprozess vom Papst an ein künftiges, im Heiligen Geist versammeltes Konzil delegieren zu können. ${ }^{7}$ Dass der Papst eine solche Appellation längst verboten hatte, interessierte Luther und seine Rechtsberater herzlich wenig.

\section{II.}

Die Entwicklung von Luthers Konzilsverständnis wurde im Jahr 1519 durch die Leipziger Disputation ${ }^{8}$ elementar beschleunigt und grundsätzlicher als zuvor ihren spätmittelalterlichen Formen entwunden. In Leipzig stritten Johannes Eck und Luther um die Bedeutung der kirchlichen Autoritäten. Während sich Eck darauf konzentrierte, Luther als Ketzer zu entlarven, hoffte Luther den päpstlichen Primatsanspruch mit Hilfe der altkirchlichen Konzilien als widerchristlich zu plausibilisieren. Im Streit um die Bedeutung des Konstanzer Konzils, auf dem Jan Hus als Ketzer verurteilt worden war, rang Eck seinem Gegner die sensationelle Aussage ab: Konzilien können nicht nur irren, sondern sie haben - wie in Konstanz

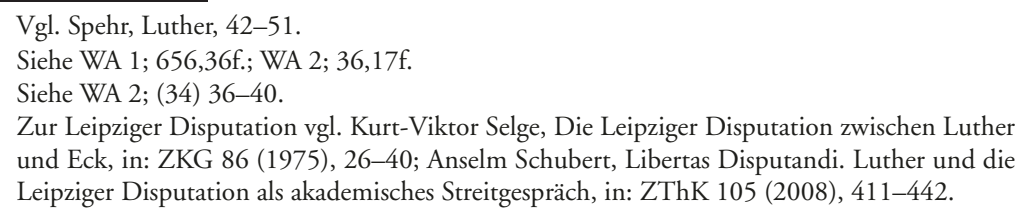


geschehen - auch bisweilen geirrt. ${ }^{9}$ Das war eine für die römische Amtskirche und romkritische Konziliaristen gleichermaßen unerhörte Aussage! Zwar suchte Luther seinerseits das altkirchliche Konzil von Nicäa aus dem Jahr 325 gegenüber dem Konstanzer Konzil aufzuwerten, doch ließ Eck eine Autoritätendifferenzierung der Konzilien nicht zu. Für ihn war Luther jetzt ein Ketzer, da er die souveräne Autorität der Konzilien in Frage gestellt hatte. $^{10}$

Nach der Leipziger Disputation ging Luther seinen eingeschlagenen reformatorischen Weg konsequent weiter. Die Heilige Schrift galt ihm jetzt als höchste kirchliche Norm. Einem Konzil kam daher nur dann Autorität zu, wenn es sich ausschließlich an der Heiligen Schrift orientierte. Weil nach Luthers Meinung dieses Kriterium den jüngeren, päpstlichen Konzilien mangelte, hätten ihre Beschlüsse keine Autorität. Im Jahr 1520 entfaltete Luther sein schriftorientiertes Konzilsverständnis.

\section{III.}

Parallel zur Kritik an den päpstlichen Konzilien begann Luther, ein Konzil für kirchenpraktische Reformen wie die Zulassung des Laienkelchs beim Abendmahl und die Wiedereinführung der Priesterehe zu fordern. ${ }^{11}$ Weil vom Papsttum keine Reform der Kirche zu erwarten war, die Christenheit aber im Glauben und im Leben durch das Evangelium gebessert werden musste, wandte sich Luther in dieser Notsituation an die weltliche Obrigkeit. Wie einleitend bereits betont, forderte er in seiner Adelsschrift Kaiser, Fürsten und politische Mandatsträger auf, die Besserung der Kirche voranzutreiben und ein Reformkonzil einzuberufen. Bezüglich des Konzilsverständnisses trat in der Adelsschrift erstmals Luthers gereifte reformatorische Konzilskonzeption an die Öffentlichkeit. Ausdruck fand diese neue Konzeption in dem Begriff des „freien, christlichen Konzils“. ${ }^{12}$ „Frei“ bedeutete hierbei für das Konzil, frei vom Papst mit dessen Dekreten zu sein, und für die Konzilsteilnehmer, frei ihre Meinung äußern zu dürfen. „Christlich“ war das Konzil, wenn es sich nach der Heiligen Schrift richtete, sich vom Heiligen Geist leiten ließ und sich als christliche Gemeindeversammlung verstand. ${ }^{13}$ Außerdem sollte es alle christlichen Gemeinschaften - und nicht nur die römische Kirche - versammeln.

\footnotetext{
Siehe WA 59; 500, 2081-2083.

Vgl. Spehr, Luther, 138-163.

Siehe u. a. WA 2; 742,24-26; WA 6; 146,13f.

Siehe u. a. WA 6; 413,27-29.

Vgl. Spehr, Luther, 217-233.
} 
Mit diesen grundlegenden Erkenntnissen waren die herrschenden kirchlichen Konzilsvorstellungen obsolet geworden. Jetzt ermöglichte das reformatorische Konzilsverständnis einerseits die Verurteilung der päpstlichen Konzilien und ihrer Beschlüsse. Andererseits eröffnete es Luther die Indienstnahme des Konzils als Ort für Kirchenreformen. Es war die Institution des „freien, christlichen Konzils“, an die er 1520 in Reaktion auf die Bannandrohungsbulle erneut appellierte. ${ }^{14}$ Das „freie, christliche Konzil“ galt ihm nun als angemessener Reformationsort. Und es galt ihm als der Ort, an dem eine unparteiische Entscheidung über seine evangeliumsgemäße Lehre gefällt werden konnte.

\section{IV.}

Allerdings trat in dem Maße, in dem sich Luthers Schriftprinzip manifestierte, seine Konzilsforderung signifikant zurück. Zudem erfuhr der mittlerweile von der Kirche gebannte Mönch auf dem Wormser Reichstag 1521, dass dieses Gremium keineswegs zur Prüfung seiner Lehre bereit war, sondern ihn - trotz großer Sympathie im Vorfeld - mit der Reichsacht belegte. Als zentraler Beweis für Luthers Ketzerei diente in Worms - von der Forschung bisher übersehen - dessen Konzilskritik und Konzilsappellation.

Seit Sommer 1521 galt Luthers Hauptanliegen der kirchlichen Reform oder Reformation, die aber nicht mehr durch ein Konzil - auch nicht durch ein freies, christliches Konzil -, sondern allein durch Gottes Wort herbeigeführt werden sollte. Ihre Umsetzung übertrug Luther der Verantwortung der christlichen Ortsgemeinde und ihrer Pfarrer. ${ }^{15}$ Für Luther hatte das Konzil als Reformationsort ausgedient. ${ }^{16}$ Selbst die drängenden kirchenorganisatorischen Fragen wollte Luther nicht durch eine Synode oder ein Provinzialkonzil geklärt wissen. Seine Abneigung gegen das konziliare Entscheidungsforum begründete er mit dem Hinweis, dass durch Konzilien nur neue menschliche Gesetze eingeführt würden, die dem Evangelium die Freiheit raubten.

14 Siehe WA 7; (74) 75-82.

15 Vgl. Spehr, Luther, 338-355.

16 Siehe WA 12; 238,20-24: Auff das wort wagen wyrs und thuns, nur zu trotz und zu widder allen Concilien, kirchen, allen menschen setzen, allen gelübden, gewonheytten, und was da widder seyn möcht oder yhe gewesen ist. Augen und oren zu, und nur gottis wort yns hertz gefasset! 
Luthers ablehnende Haltung zur Institution des allgemeinen Konzils blieb dennoch nicht sein letztes Wort. Während Luther dem Konzil keine positive Gestaltungskraft im Reformationsprozess mehr zuwies, hatten die Reichsstände das Konzilsthema in den 1520er Jahren aufgegriffen und zur Klärung der Glaubensfrage profiliert. Im kirchenpolitischen Ringen um die wahre Lehre übernahmen die Reichsstände Luthers 1520 entfalteten Begriff eines „freien, christlichen Konzils“. Sie ergänzten ihn um die Forderung „in deutschen Landen". ${ }^{17}$

Neu belebt wurde die Diskussion um das Konzil, als der Papst mit seiner Konzilsausschreibung nach Mantua 1537 vermeintlich ernst machte. Durch seine 1520 vorgegebenen Linien war Luther auf den Diskurs bestens vorbereitet und griff jetzt erneut auf seine damals entwickelte Formel zurück. Luther votierte gegenüber seinem Landesherrn für eine Konzilsteilnahme der Protestanten unter der Bedingung, dass der Kaiser und somit die weltliche Obrigkeit das Konzil leite. Auf dem Konzil sollte nach Luthers Meinung keineswegs über die evangelische Lehre entschieden werden. Vielmehr sah Luther in dem allgemeinen Konzil einen Ort, an dem den Altgläubigen der evangelische Glaube öffentlichkeitswirksam vermittelt werden könne. In diesem „missionarischen“ Sinne konnte er ein Konzil als Reformationsort erneut propagieren.

Institutionell war das Konzil für ihn nichts anderes als ein Konsistorium, Hofgericht oder Kammergericht, das in durch Irrlehren bedrohten Notzeiten zusammenkomme und das Evangelium verteidige. In seiner bedeutenden Schrift „Von den Konziliis und Kirchen"18 eignete er die Aufgabe der täglichen Glaubensverteidigung den Pfarrern und Schulmeistern zu. Zukunftsgewandt betonte er: „Denn wo wir die Concilia ja nicht haben können, so sind die Pfarrhen und Schulen, wiewol kleine, doch ewige und nützliche Concilia. ${ }^{\text {"19 }}$

\footnotetext{
Vgl. DRTA. JR 3; 447-452 (Mandat des Reichsregiments vom 6. März 1523).

WA 50; (488) 509-653.

WA $50 ; 617,22-24$.
} 